\title{
Possible action of vasohibin-1 as an inhibitor in the regulation of vascularization of the bovine corpus luteum
}

\author{
Koumei Shirasuna, Ayumi Kobayashi, Akane Nitta, Sayo Nibuno, Kiemi Sasahara, \\ Takashi Shimizu, Heinrich Bollwein ${ }^{1}$ and Akio Miyamoto \\ Graduate School of Animal and Food Hygiene, Obihiro University of Agriculture and Veterinary Medicine, Obihiro \\ 080-8555, Japan and ${ }^{1}$ Clinic for Cattle, University of Veterinary Medicine Hannover, D-30173 Hannover, Germany \\ Correspondence should be addressed to K Shirasuna, who is now at Division of Bioimagin Sciences, Center for Molecular \\ Medicine, Jichi Medical University, 3311-1 Yakushiji, Shimotsuke, Tochigi 329-0498, Japan; Email: shirasuna@jichi.ac.jp
}

\begin{abstract}
The development of the corpus luteum $(\mathrm{CL})$, which secretes large amounts of progesterone to establish pregnancy, is accompanied by active angiogenesis, vascularization, and lymphangiogenesis. Negative feedback regulation is a critical physiological mechanism. Vasohibin-1 (VASH1) was recently discovered as a novel endothelium-derived negative feedback regulator of vascularization. We therefore investigated the expression of VASH1 in the bovine CL. Expression of VASH1 mRNA and protein was predominantly localized to luteal endothelial cells (LECs). VASH1 expression in the CL was constant through the early to late luteal phases and decreased during CL regression relating with the action of luteolytic prostaglandin $\mathrm{F}_{2 \alpha}$ in vivo. To investigate the role of VASH1, we determined whether VASH1 treatment affects angiogenesis and/or lymphangiogenesis using LECs and lymphatic endothelial cells (LyECs) in vitro. Vascular endothelial growth factor A (VEGFA) stimulated the expression of VASH1 in LECs but not in LyECs, and VASH1 completely blocked VEGFA-induced formation of capillary-like tube structures of LECs and LyECs in vitro. In summary, VASH1 is predominantly located on LECs in the bovine $\mathrm{CL}$ and inhibits the angiogenic and lymphangiogenic actions of VEGFA. Bovine CL therefore has a VEGFA-VASH1 system that may be involved in regulation of luteal function, especially in the development of the CL. The results indicate that VASH1 has the potential to act as a negative feedback regulator of angiogenesis and lymphangiogenesis in the $C L$ in cows.
\end{abstract}

Reproduction (2012) 143 491-500

\section{Introduction}

The corpus luteum (CL) is an essential organ for maintaining pregnancy and functions by secreting progesterone $\left(\mathrm{P}_{4}\right.$; Rodgers et al. 1988). The bovine CL develops rapidly within $2-3$ days after ovulation; this development is accompanied by active angiogenesis, vascularization, and lymphangiogenesis (Augustin et al. 1995, Schams \& Berisha 2004, Nitta et al. 2011). The CL is a highly vascularized organ with a vascular density exceeding those of most tumors. If pregnancy is not successfully established, the $C L$ is functional for only 17-18 days and must then regress within a few days to allow for the next cycle of ovulation (McCracken et al. 1981). In the cow, luteal regression is induced by uterine prostaglandin (PG) $F_{2 \alpha}$ together with disruption of the vascular system, including blood and lymphatic vessels (Niswender et al. 1976, Acosta et al. 2002, Hojo et al. 2009, Nitta et al. 2011). Vascular systems and endothelial cells within the $\mathrm{CL}$ thus have essential roles in luteal function.

Angiogenesis, the formation of new blood vessels, is crucial for various developmental or remodeling processes involved in physiological and pathophysiological conditions. Physiological angiogenesis occurs not only during organ growth and development and wound healing but also during reproduction in the uterus and ovary. Angiogenesis is generally regulated by the local balance between stimulatory and inhibitory angiogenic factors (Sato \& Sonoda 2007, Sato 2011). The most important stimulatory angiogenic factors are vascular endothelial growth factor A (VEGFA) and basic fibroblast growth factor (FGF2), while, angiogenesis inhibitors include thrombospondin-1 (Good et al. 1990), pigmented epithelium-derived factor (Tombran-Tink et al. 1991), angiostatin (O'Reilly et al. 1994), and endostatin (O'Reilly et al. 1997). Negative feedback regulation is a critical physiological mechanism and has been demonstrated to control a wide range of phenomena. However, little is known about endogenous inhibitors of angiogenesis in the bovine $\mathrm{CL}$.

Watanabe et al. (2004) recently discovered a novel endothelium-derived negative feedback regulator of angiogenesis, vasohibin-1 (VASH1), by searching for VEGFA-inducible genes in human endothelial cells using DNA microarray analysis and isolating the previously uncharacterized gene VASH1. Human 
VASH1 protein is composed of 365 amino acid residues, with no detectable glycosylation. VASH1 is predominantly expressed on endothelial cells based on the immunohistochemistry data in humans and mice. Recombinant VASH1 inhibits endothelial cell migration, proliferation, and network formation in vitro as well as angiogenesis in vivo (Watanabe et al. 2004, Hosaka et al. 2009, Heishi et al. 2010). Furthermore, the coadministration of VASH1 with VEGFA has been reported to block, almost completely, not only VEGFA-induced angiogenesis but also lymphangiogenesis in the mouse cornea (Heishi et al. 2010).

Given its role in angiogenesis and lymphangiogenesis, we hypothesized that VASH1 is involved in the function of the $\mathrm{CL}$, but expression of VASH1 in the bovine $\mathrm{CL}$ has not been described. Therefore, in the present study, we investigated the local production and possible role of VASH1 in the bovine $\mathrm{CL}$, by examining the mRNA expression and localization of $\mathrm{VASH} 1$ during the formation, maturation, and regression of the $\mathrm{CL}$ in cows. We also explored whether VASH1 is involved in angiogenesis and/or lymphangiogenesis using luteal endothelial cells (LECs) and lymphatic endothelial cells (LyECs) in vitro.

\section{Results}

VASH1 $\mathrm{mRNA}$ and protein expression in the CL during the estrous cycle and $P G F_{2 \alpha}$-induced luteolysis

Figure $1 \mathrm{~A}, \mathrm{~B}, \mathrm{C}$ and $\mathrm{D}$ shows VASH1 mRNA and protein expression in the $\mathrm{CL}$ during the estrous cycle (Fig. $1 \mathrm{~A}$ and B) and PGF $_{2 \alpha}$-induced luteolysis (Fig. 1C and D). During the estrous cycle, VASH1 mRNA expression significantly increased from the early to the mid-luteal CL (Fig. 1A, $P<0.05)$, while $\mathrm{VASH} 1$ protein expression remained constant from the early through the late luteal phase (Fig. 1B). In the regressing $\mathrm{CL}$, expression of VASH1 mRNA and protein was significantly decreased (Fig. 1A and $\mathrm{B}, P<0.05)$. During $\mathrm{PGF}_{2 \alpha}$-induced luteolysis, expression levels of VASH1 mRNA and protein in the $\mathrm{CL}$ significantly decreased beginning at $30 \mathrm{~min}$ or $2 \mathrm{~h}$ respectively (Fig. $1 \mathrm{C}$ and $\mathrm{D}, P<0.05$ ). After $\mathrm{PGF}_{2 \alpha}$ injection, plasma $\mathrm{P}_{4}(0 \mathrm{~h}=5.3 \pm 0.5 \mathrm{ng} / \mathrm{ml})$ significantly decreased at $30 \mathrm{~min}$ and $2 \mathrm{~h}$ (about $70 \%$ of $0 \mathrm{~h}$ ) and was further reduced at $12 \mathrm{~h}$ by $25 \%$ of $0 \mathrm{~h}$ (data not shown).

\section{Localization of VASH1 mRNA and protein in the $C L$}

VASH1 mRNA expression was detected in various cell and tissue types by RT-PCR (Fig. 2A). The bovine midcycle CL expressed VASH1 mRNA. Cultured (passages 5-8) LECs also showed relatively high expression of VASH1 mRNA, while cultured (passages 5-8) iliac LyECs and steroidogenic luteal cells (SCs) expressed VASH1 mRNA at lower levels. These results suggest that the low detectable signal of VASH1 mRNA in isolated LyECs and

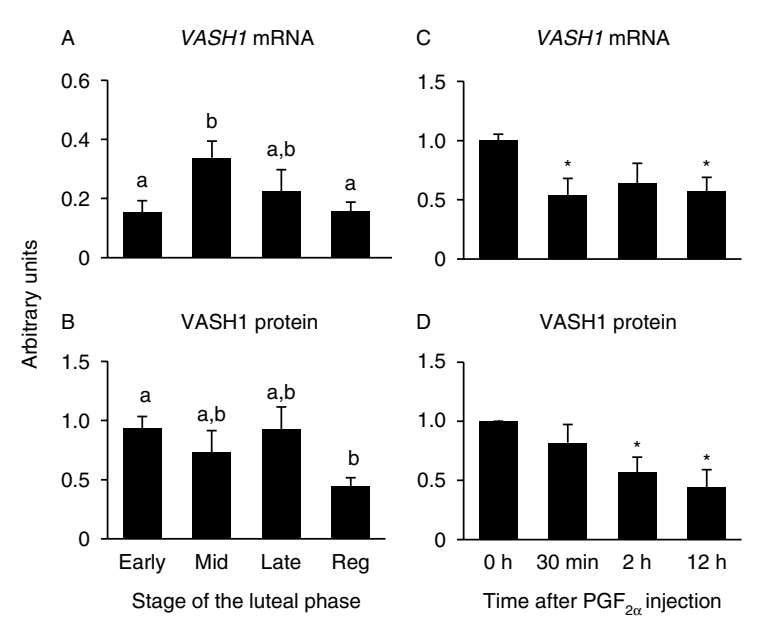

Figure 1 Changes in VASH1 mRNA and protein expression in the bovine CL. VASH1 mRNA expression (A) and protein expression (B) in the bovine $\mathrm{CL}$ during the estrous cycle $(n=4-5 /$ stage). VASH1 mRNA (C) and protein (D) expression in the bovine $\mathrm{CL}$ during $\mathrm{PGF}_{2 \alpha^{-}}$-induced luteolysis $(n=5 /$ stage). All values are shown as mean \pm S.E.M. Different superscript letters ( $\mathrm{a}$ and $\mathrm{b}$ ) and * (compared with $0 \mathrm{~h}$ ) indicate significant differences $(P<0.05)$ as determined by ANOVA followed by Bonferroni's multiple comparison test.

SCs could be due to contamination of the cell preparations with microvascular cells.

To determine the localization of VASH1 protein depending on cell types, VASH1 immunohistochemical staining was compared with that against von Willebrand factor (VWF, a marker of the vascular endothelial cells) or LYVE1 (a marker of LyECs). Figure 2B, C, D and E shows a series of sections of the bovine mid-cycle $\mathrm{CL}$ stained for VWF-VASH1 and LYVE1-VASH1 respectively. Figure 2B shows VWF-positive endothelial cells in the large blood vessels (black arrowhead) and microcapillary vessels (red arrowheads), while Fig. 2C shows that VASH1 protein was localized to the same microcapillary vessels as VWF (red arrowheads) but not to the large blood vessels (white arrowhead). Similarly, Fig. 2D shows LYVE1-positive LyECs in the bovine CL (green arrowheads), but Fig. 2E shows that the VASH1 protein did not co-localize with LYVE1 (gray arrowheads). Like VASH1, LYVE1 was not detected in VWF-positive large blood vessels (Fig. 2D, white arrowhead). In the present study, VASH1 protein was barely detectable in SCs, suggesting that the LECs of microcapillary and/or small blood vessels are the predominant VASH1-expressing cells in the bovine CL.

\section{Effect of VEGFA and VASH1 on VEGFA and VASH1 expression in LECs and LyECS}

We investigated the effects of VEGFA and VASH1 on LECs and LyECs. Figure 3 shows the changes in VEGFA and VASH 1 mRNA and protein expression levels in LECs and LyECs after treatment with VEGFA or VASH1 $(1,10$ or $100 \mathrm{ng} / \mathrm{ml})$. VEGFA at $10 \mathrm{ng} / \mathrm{ml}$ significantly increased 
A
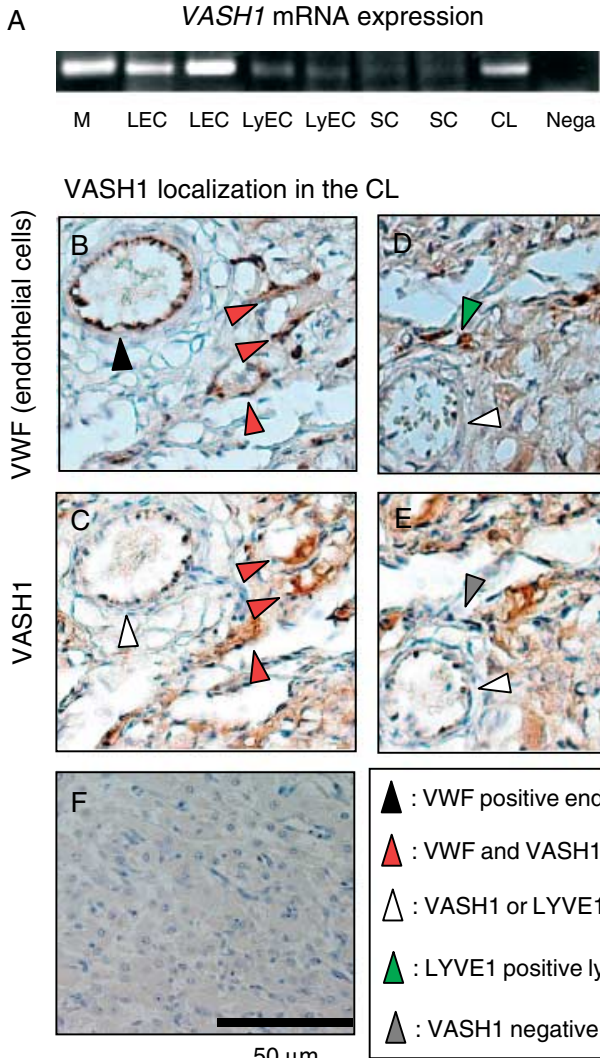

$50 \mu \mathrm{m}$
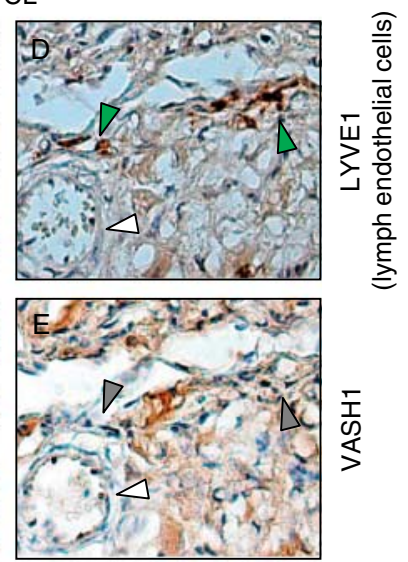

$\Lambda$ : VWF positive endothelial cells (EC)

$\triangle:$ VWF and VASH1 double positive EC

$\triangle:$ VASH1 or LYVE1 negative EC

$\triangle:$ LYVE1 positive lymph EC

$\triangle:$ VASH1 negative lymph EC

Figure 2 mRNA expression and localization of VASH1 in the bovine CL. Panel A shows the mRNA expression of $\mathrm{VASH} 1$ in various cell or tissue types, such as cultured LECs, cultured iliac LyECs, SCs, and CL (midluteal phase). $M$ indicates DNA mass ladder. Panels B, C, D and E show the immunohistochemical localization of VASH1 in the mid-CL during the estrous cycle. VWF-positive cells were detected among the endothelial cells of both large blood and microcapillary vessels (B). The vascular endothelial cells in microcapillary vessels $(C$, red arrowheads) but not large blood vessels (white arrowhead) also stained for VASH1. D shows LYVE1-positive lymphatic endothelial cells in the bovine $\mathrm{CL}$ (green arrowheads), while (E) shows that VASH1 protein did not co-localize with LYVE1 (gray arrowheads). The specificity of the staining was monitored in a negative control section (F) by replacing the antibody with goat anti-rabbit IgG. The scale bars in all images represent $50 \mu \mathrm{m}$.

VASH1 mRNA and protein expression in LECs (Fig. 3A and $\mathrm{B}$ ), while $\mathrm{VASH} 1$ at $1-100 \mathrm{ng} / \mathrm{ml}$ had no effect on VEGFA mRNA expression in LECs (Fig. 3C). In LyECs, neither VEGFA nor VASH1 treatment had any effect on VASH1 or VEGFA mRNA expression (Fig. 3D and E).

\section{Effects of VEGFA and VASH1 on proliferation of LECs and LyECS}

We next examined the effects of VEGFA and VASH1 on the proliferation of LECs and LyECs in vitro (Fig. 4A and B). The data show that neither VEGFA $(1-100 \mathrm{ng} / \mathrm{ml})$, nor VASH1 $(100 \mathrm{ng} / \mathrm{ml})$ nor a combination of VEGFA and VASH1 had any effect on the proliferation of LECs (Fig. 4A). In LyECs, VEGFA (10 and $100 \mathrm{ng} / \mathrm{ml}$ ) significantly stimulated

cell proliferation for $24 \mathrm{~h}$ in culture. Although VASH1 had no individual effect on the proliferation of LyECs, it did significantly inhibit VEGFA-induced cell proliferation (Fig. 4B).

\section{Effects of VEGFA and VASH1 on capillary-like tube formation by LECs and LyECs}

We next examined the effects of VEGFA and VASH1 on capillary-like tube formation of LECs and LyECs in vitro using a matrigel assay (Figs 5 and 6). The data show that VEGFA at 10 and $100 \mathrm{ng} / \mathrm{ml}$ significantly stimulated the formation of capillary-like tube structures (a linear array of cells with junctional complexes, not a cylindrical structure) by both LECs and LyECs, compared with that by control cells, $8 \mathrm{~h}$ posttreatment (Figs 5A and 6A). In both LECs and LyECs, while VASH1 had no individual effect on capillary-like tube formation (Figs $5 B, G$ and $6 B$ and $G$ ), it significantly inhibited the formation of VEGFA-induced capillary-like tube structures (Figs 5B, C and F and 6B, C and F). Typical images of tube formation by control, VEGFA-treated, VASH1-treated, and VEGFA and VASH1 combinationtreated LECs and LyECs are shown in Figs 5B, C, D and $\mathrm{G}$ and $6 \mathrm{~B}, \mathrm{C}, \mathrm{D}$ and $\mathrm{G}$ respectively.

\section{Discussion}

In the present study, we have evaluated the expression of VASH1 in bovine $\mathrm{CL}$ tissue during the estrous cycle and $\mathrm{PGF}_{2 \alpha}$-induced luteolysis. Both immunohistochemical and mRNA expression analyses showed that VASH1 was predominantly localized to LECs relative to SCs and LyECs. VASH1 expression was consistent from the early through the late luteal phases but decreased in the $\mathrm{CL}$ during regression due to the luteolytic action of $\mathrm{PGF}_{2 \alpha}$. VEGFA treatment stimulated the expression of VASH1 in LECs, while VASH1 treatment completely blocked VEGFA-induced capillary-like tube structure formation by LECs and LyECs in vitro. Therefore, the bovine $\mathrm{CL}$ has a VEGFA-VASH1 system that may be involved in luteal function, especially the development of the $\mathrm{CL}$ in cows.

Watanabe et al. (2004) proposed that VASH1 is an endothelium-derived negative feedback regulator of angiogenesis. VASH1 has been reported to be expressed predominantly in the endothelial cells of the artery, corneal, retina, lymph node, endometrium, glomerulus, and tumors in humans (Yamashita et al. 2006, Yoshinaga et al. 2008, Hosaka et al. 2009, Tamaki et al. 2009) and mice (Kimura et al. 2009, Heishi et al. 2010, Li et al. 2010). Expression studies in human endothelial cells revealed that VASH1 protein localized to the nucleus and cytoplasm (Watanabe et al. 2004, Kern et al. 2008). In cows in the present study, strong expression of both VASH1 mRNA and protein was detected in LECs. Moreover, SCs in the CL and LyECs in cows did express very low levels of VASH1. This finding is consistent with previous studies in which 

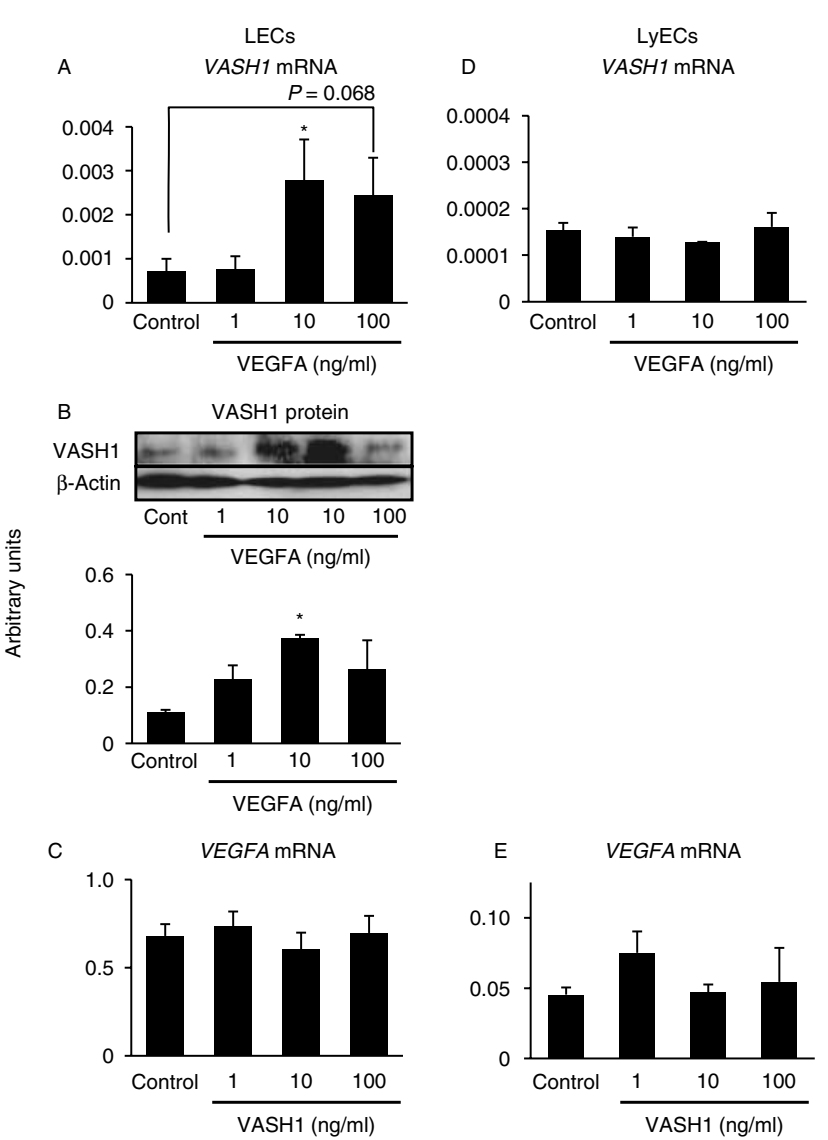

Figure 3 VASH1 and VEGFA expression profiles in LECs and LyECs.

This figure shows the effects of VEGFA or VASH1 on the expression of VASH1 or VEGFA in cultured LECs (A, B and C) and cultured iliac LyECs (D and $\mathrm{E}$ ) respectively. VEGFA stimulated $V A S H 1$ mRNA expression in cultured LECs (A) but not LyECs (D). VEGFA also stimulated VASH1 protein expression in cultured LECs (B). Representative photographs of western blots for VASH1 (42 kDa) and $\beta$-actin (37 kDa) are shown (B). In contrast, VASH1 had no effect on VEGFA mRNA expression in either cultured LECs (C) or cultured iliac LyECs (E). All values are shown as mean \pm S.E.M. ( $n=4 /$ group). *Significant difference $(P<0.05$, compared with control) as determined by ANOVA followed by Bonferroni's multiple comparison test.

weak VASH1 expression was observed in aortic smooth muscle cells and fibroblast, peripheral blood mononuclear cells, and synovial lining cells in humans (Kern et al. 2008, Miyake et al. 2009). In addition, VASH1 expression was observed in blood, vascular tissue, spleen, heart, placenta, embryo, and brain in humans, mice, and chickens (Shibuya et al. 2006, Nimmagadda et al. 2007), suggesting that VASH1 might have further functions not only in angiogenesis but also in organ development or immunobiology.

VASH1 was discovered as a VEGFA-induced antiangiogenic factor (Watanabe et al. 2004). Recombinant VASH1 completely inhibited network formation by endothelial cells in vitro as well as angiogenesis in vivo (Watanabe et al. 2004). Additionally, administration of recombinant or adenovirus vector encoded
VASH1 blocked not only VEGFA-induced angiogenesis but also lymphangiogenesis in the mouse cornea (Heishi et al. 2010). These findings indicated that VASH1 is a key negative regulatory component of the vascular system. Therefore, in the present study, we investigated the expression profile of VASH1 and its function in LECs and LyECs in vitro. It has been clearly demonstrated that VEGFA stimulates the expression of both VASH1 mRNA and protein in a dose- and time-dependent manner in human endothelial cells in vitro (Watanabe et al. 2004). As in previous studies, VEGFA in the present study increased both VASH1 mRNA and protein expression in the bovine LECs but not in LyECs. Importantly, VASH1 treatment completely suppressed VEGFA-stimulated capillary tube-like structure formation by both LECs and LyECs and proliferation of LyECs. These findings suggest that $\mathrm{VASH} 1$ is a key negative feedback regulatory factor of vascularization, including angiogenesis and lymphangiogenesis.

The bovine $\mathrm{CL}$ is a highly vascularized organ and produces various angiogenic factors. The highest expression levels of VEGFA and FGF2 were detected

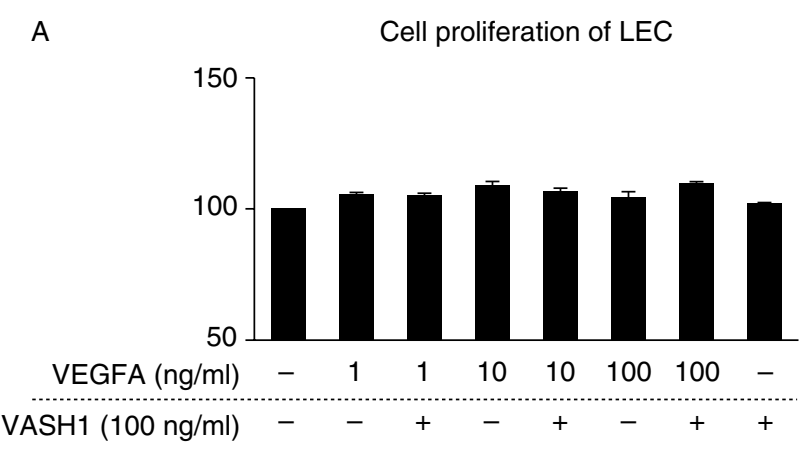

B

Cell proliferation of LyEC

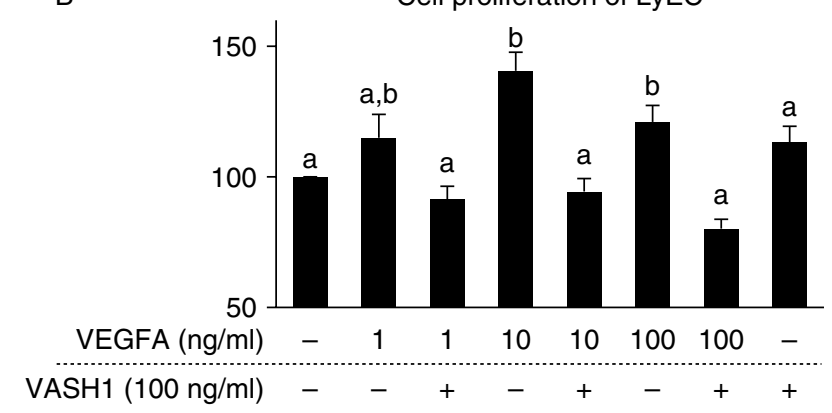

Figure 4 VEGFA and VASH1-induced cell proliferation of LECs and LyECs. The effects of VEGFA and VASH1 on the proliferation of cultured LECs (A) and cultured iliac LyECs (B) are shown. VEGFA (1-100 ng/ml), VASH1 $(100 \mathrm{ng} / \mathrm{ml})$, and a combination of VEGFA and VASH1 had no effect on proliferation of cultured LECs (A). In cultured iliac LyECs, VEGFA (10 and $100 \mathrm{ng} / \mathrm{ml}$ ) significantly stimulated cell proliferation. Although VASH1 had no individual effect on the proliferation of cultured iliac LyECs, it significantly inhibited VEGFA-induced cell proliferation (B). All values are shown as mean \pm s.E.M. ( $n=4$ /group). Different superscript letters (a and b) indicate significant differences $(P<0.05)$ as determined by ANOVA followed by Bonferroni's multiple comparison test. 
A
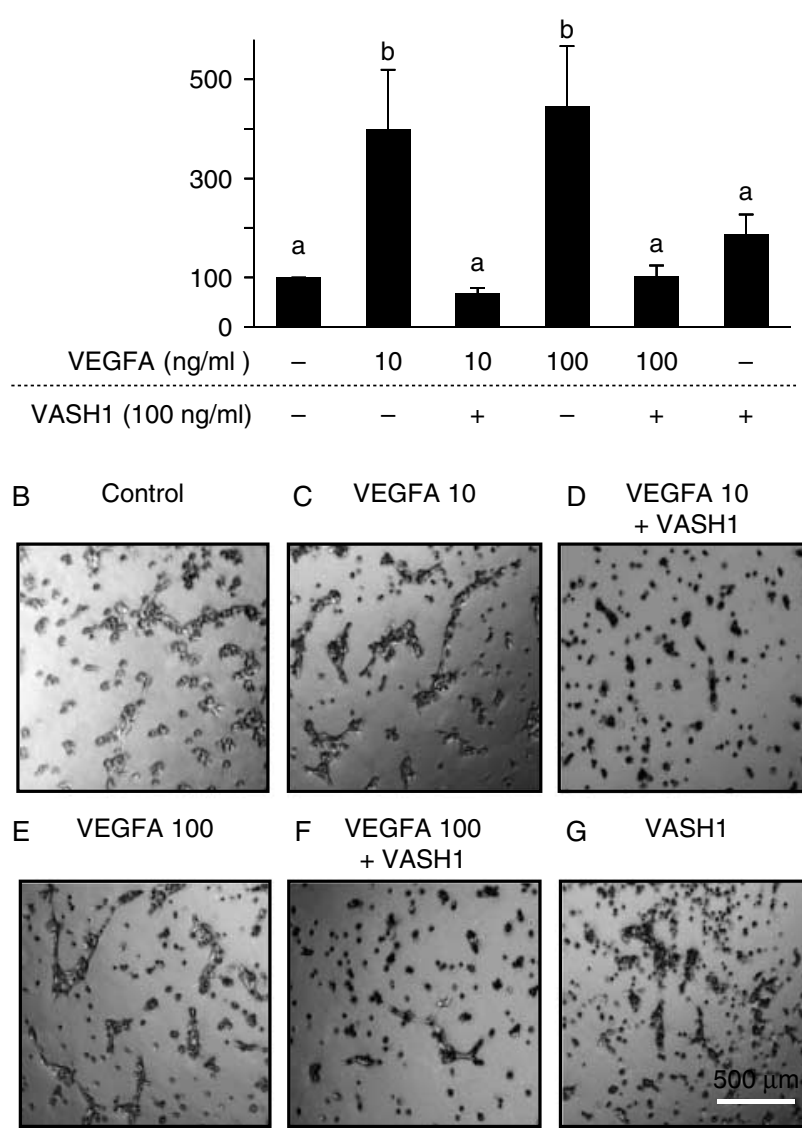

C VEGFA 10

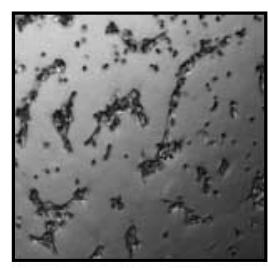

F VEGFA 100 $+\mathrm{VASH} 1$

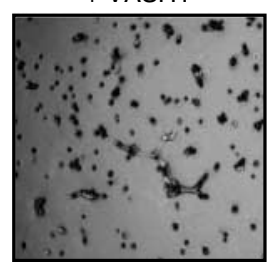

E VEGFA 100

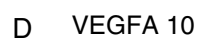
$+\mathrm{VASH} 1$

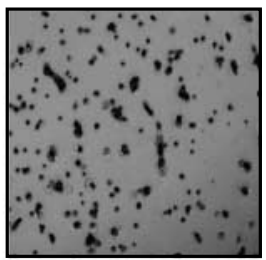

G VASH1

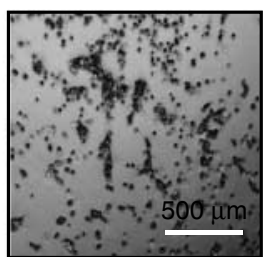

Figure 5 VEGFA and VASH1-induced capillary-like tube formation by LECs. The effects of VEGFA and VASH1 on capillary-like tube formation by cultured LECs in vitro in a matrigel assay are shown. VEGFA at 10 and $100 \mathrm{ng} / \mathrm{ml}$ significantly stimulated the capillary-like tube structure formation by cultured LECs relative to that by control cells at $8 \mathrm{~h}$ posttreatment (A). VASH1 had no individual effect on capillary-like tube formation, but it significantly inhibited VEGFA-induced capillarylike tube structure formation. Typical images of tube formed by cultured LECs in each experimental group are shown in B, C, D, E, F and G. All values are shown as mean \pm s.E.M. ( $n=4$ /group). Different superscript letters $(a$ and $b)$ indicate significant differences $(P<0.05)$ as determined by ANOVA followed by Bonferroni's multiple comparison test.

during development of the $\mathrm{CL}$ and were continuously expressed in the mature CL in cows (Schams et al. 1994, Berisha et al. 2000). VASH1 protein expression was also at its highest level in the early $\mathrm{CL}$, whereas VASH1 mRNA expression was increased from the early to mid-CL in the present study. Excessive production of angiogenic factors such as VEGFA and FGF2 may induce disordered angiogenesis and lymphangiogenesis, suggesting that VASH1 is involved in the homeostatic regulation of the luteal environment to prevent inappropriate vascular system development. In fact, VASH1 had no individual effect on angiogenesis but did suppress angiogenesis and lymphangiogenesis induced by VEGFA or FGF2 in vivo and in vitro in both the present study and previous reports (Watanabe et al. 2004, Shibuya et al. 2006, Heishi et al. 2010). Additionally, VEGFA and FGF2 are expressed at higher levels in breast carcinoma and endometrioid adenocarcinoma in humans (Yoshinaga et al. 2008). In the mouse tumor model induced by the injection of Lewis lung carcinoma cells into the subcutaneous tissue, tumors grew bigger in $V A S H 1^{-/-}$mice than in wild-type mice, and the vascular area was increased and the tumor vessels were more immature, lacking mural cells in $\mathrm{VASH} 1^{-1-}$ mice (Hosaka et al. 2009). These data indicate that endogenous VASH1 participates in the inhibition of tumor angiogenesis and the maturation of vascular vessels.

In the present study, VASH1 expression significantly decreased in the regressing $C L$ whether the regression was due to the estrous cycle or $\mathrm{PGF}_{2 \alpha}$-induced luteolysis. This

A Tube formation of LyEC

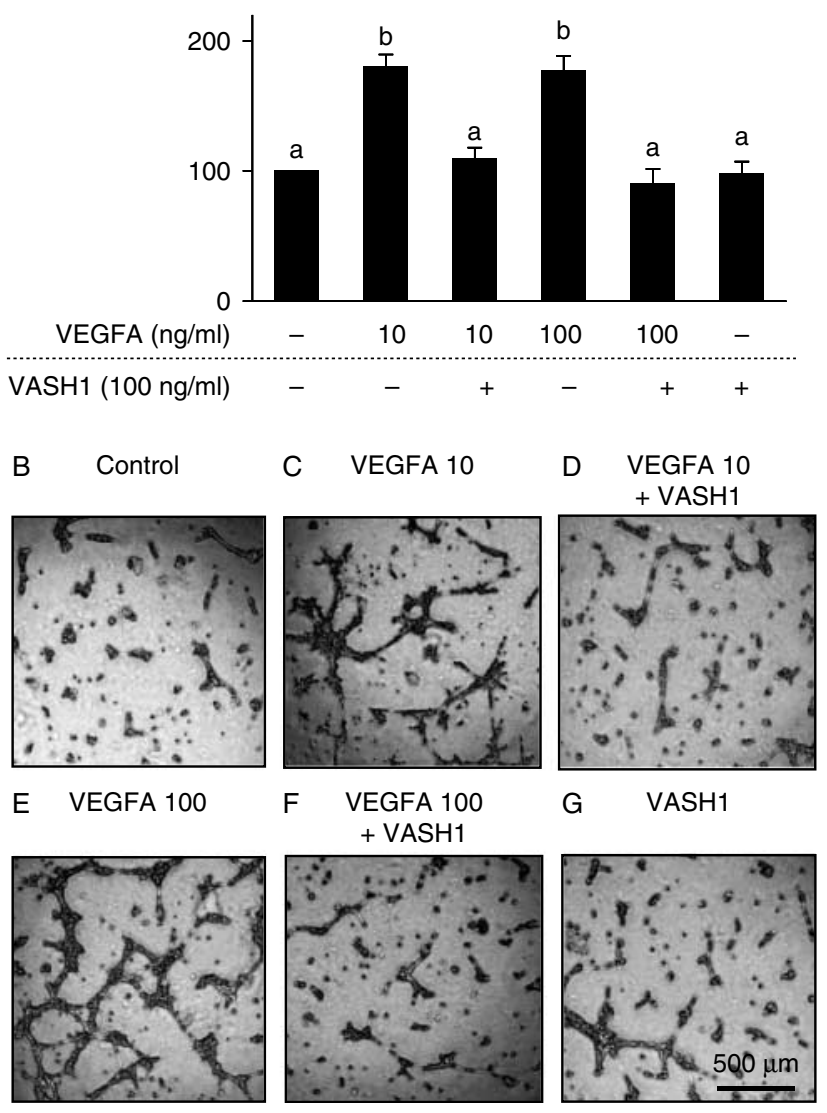

Figure 6 VEGFA and VASH1-induced capillary-like tube formation by LyECs. The effects of VEGFA and VASH1 on capillary-like tube formation of cultured iliac LyECs in vitro in a matrigel assay are shown in figure. VEGFA at 10 and $100 \mathrm{ng} / \mathrm{ml}$ significantly stimulated capillarylike tube structure in cultured iliac LyECs relative to that by control cells at $8 \mathrm{~h}$ posttreatment (A). VASH1 had no individual effect on capillarylike tube formation, but it significantly inhibited VEGFA-induced capillary-like tube structure. Typical images of tube formed by cultured iliac LyECs in each experimental group are shown in B, C, D, E, F and G. All values are shown as mean \pm s.E.M. ( $n=4$ /group). Different superscript letters $(\mathrm{a}$ and $\mathrm{b})$ indicate significant differences $(P<0.05)$ as determined by ANOVA followed by Bonferroni's multiple comparison test. 
finding is supported by previous studies in which the expression of VEGFA was acutely inhibited and redundant vascular system gradually disrupted during luteolysis in cows (Neuvians et al. 2004, Hojo et al. 2009, Berisha et al. 2010). On the other hand, it is well known that acceleration of luteolysis mobilizes macrophages into the luteal tissue via monocyte chemoattractant protein-1 (MCP1) expression (Penny 2000, Cavicchio et al. 2002, Townson et al. 2002). Interestingly, VASH1 administration significantly suppressed macrophage infiltration and the expression of MCP1 as well as inhibiting angiogenesis in diabetic mice (Nasu et al. 2009). The infiltration of macrophages was also significantly reduced by adenovirus-mediated VASH1 injection into the mouse femoral artery (Yamashita et al. 2006). Moreover, macrophage numbers and MCP1 expression are at low levels while VASH1 expression is at higher levels in the mid to late luteal phases compared with the regressing CL (Penny 2000, Townson et al. 2002). Therefore, it has been suggested that downregulation of VASH1 during luteolysis contributes to a suitable microenvironment for recruiting macrophages into the CL. However, Yamashita et al. (2006) suggested that the inhibition of macrophage infiltration may be due to the inhibition of angiogenesis, as VASH1 did not affect the migration of macrophages in that study. Further investigation is required to determine 1) why VASH1 is downregulated during luteolysis, 2) the relationships between the decrease of VASH1, and the potential role of $\mathrm{PGF}_{2 \alpha}, \mathrm{TNF} \alpha$, and IFN $\gamma$, and 3) whether VASH1 regulates the migration of immune cells directly or indirectly in cows.

Antibody against VEGFR2 but not FLT1 (VEGFR1) completely blocked the intracellular signaling cascade that mediates induction of VASH1 by VEGFA (Shimizu et al. 2005). Protein kinase C (PRKC (PKC)) is an important downstream intracellular signaling mediator of VEGFR2. Upon VEGFA stimulation, the activation of PKC $\delta$ peaked at $10 \mathrm{~min}$, followed by increased VASH1 expression, and a specific inhibitor of PKC $\delta$ completely suppressed the upregulation of VASH1 induced by VEGFA (Shimizu et al. 2005). These findings demonstrated that the induction of VASH1 expression is initiated by VEGFR2 signaling and $\mathrm{PKC} \delta$ is thought to play a principal role in VASH1 expression. As negative regulator of vascularization, VASH1 should act to inhibit the angiogenic and lymphangiogenic activity of VEGFA. However, the mechanisms by which VASH1 acts are controversial; treatment with adenovirus encoded-VASH1 suppressed the increase of VEGFR2 expression and its phosphorylation in mice (Nasu et al. 2009, Zhou et al. 2010), whereas VASH1 did not inhibit VEGFA-induced VEGFR2 phosphorylation in human umbilical vein endothelial cells (Watanabe et al. 2004). In the present study, VASH1 treatment did not affect the mRNA expression of VEGFR2 in either LECs or LyECs in cows (data not shown). In addition, the specific VASH1 receptor is yet to be discovered. A correct understanding of the VEGFA-VASH1 system, including its functions, signaling, and receptor will guide novel research into both physiological and pathophysiological vascularization.

In summary, the present results demonstrate the expression of VASH1, especially in blood vascular endothelial cells in the bovine $\mathrm{CL}$ and clearly show that VASH1 inhibits VEGFA-stimulated capillary liketube formation by both LECs and LyECs in vitro. Taken together, these results indicate that VASH1 may act as a negative feedback regulator of angiogenesis and lymphangiogenesis in the $\mathrm{CL}$ in cows.

\section{Materials and Methods}

The CLs were collected at the Field Center of Animal Science and Agriculture, Obihiro University and the Clinic for Cattle, University of Veterinary Medicine Hannover, Germany. Each experimental procedure complied with the ethics committee on animal right protection Oldenburg, Germany in accordance with German legislation on animal rights and welfare (file reference number 33.9-42502-04-07/1275) and the Guidelines for the Care and Use of Agricultural Animals of Obihiro University.

\section{Reagents}

DMEM/nutrient mixture and Ham's F-12 medium (1:1), PBS, amphotericin B, gentamicin, Tween-20, anti- $\beta$-actin mouse monoclonal (clone AC-15 antibody), ECL Western Blotting Detection System, and $0.3 \% \mathrm{H}_{2} \mathrm{O}_{2}$ were purchased from Sigma; BSA was purchased from Wako (Osaka, Japan); TRIzol reagent was purchased from Invitrogen Corporation; cell culture plates $(24,48$, or 96 wells/plate) were purchased from Nunc (Roskilde, Denmark); optimal cutting temperature (OCT) compound was purchased from Sakura Finetechnical (Tokyo, Japan); GNRH was purchased from Intervet (Unterschleißheim, Germany); DNase using a commercial kit was purchased from SV total RNA Isolation System: Promega Co.; THE RNA storage Solution was purchased from Ambion, Inc. (Austin, TX, USA); DNA purification kit SUPRECTM-01 was purchased from TaKaRa Bio., Inc. (Otsu, Japan); 4\% Block Ace Powder was purchased from DS Pharma Biomedical (Osaka, Japan); antimouse-LYVE1 rabbit polyclonal antibody was purchased from Abcam (Cambridge, UK); BD matrigel basement membrane was purchased from BD Biosciences (Bedford, MA, USA); recombinant bovine VEGFA was purchased from Kingfisher Biotech, Inc. (St Paul, MN, USA); Protease Inhibitor Cocktail and WST-1 were purchased from Roche; $70 \mu \mathrm{m}$ filter (Cell Straner, REF 352350) was purchased from BD Falcon (Franklin Lakes, NJ, USA); PVDF membranes were purchased from Bio-Rad Laboratories (Hercules, CA, USA); lymphoprep was purchased from Axis-Shield (Oslo, Norway); HRP-conjugated anti-rabbit IgG antibodies were purchased from GE Healthcare (Ltd, Buckinghamshire, UK); HRP-conjugated anti-mouse IgG antibodies were purchased from Rockland Immunochemicals, Inc. (Gilbertsville, PA, USA); anti-human VWF rabbit polyclonal antibody (A0082) was purchased from Dako Denmark A/S (Glostrup, Denmark); biotinylated goat anti-rabbit BA-1000 
IgG and avidin-biotin reagent (PK-6100, Vectastain ABC kit) were purchased from Vector Laboratories, Inc. (Burlingame, CA, USA); anti-human-VASH1 rabbit polyclonal antibody was purchased from Phoenix Pharmaceuticals, Inc. (Burlingame, CA, UK); VASH1 recombinant protein was purchased from Abnova Corporation (Taipei, Taiwan).

\section{Collection of the bovine $C L$}

\section{CLs during the estrous cycle}

To investigate the localization of VASH1, ovaries were collected from a local slaughterhouse in Obihiro, Japan. The stage of the estrous cycle was defined by macroscopic observation of the ovaries (follicles and CL; size, surface, and color) and the uterus (size, consistency, connective tissue, and mucus) as described previously (Miyamoto \& Schams 1991, Miyamoto et al. 2000). The stages of the estrous cycle $(n=4-5$ in each stage) were estimated as follows: early (days 3-5), mid (days 8-12), late (days 13-15), and regression (days $18<$ ).

\section{CLs during $\mathrm{PGF}_{2 \alpha}$-induced luteolysis}

For collecting the CL during luteolysis, 20 normal cyclic German Holstein cows in University of Veterinary Medicine Hannover, Germany were used. The day of estrus was designated as day 0. Cows ( $n=5$ for each time point) at the mid-luteal phase (days 10-12) were injected with $\mathrm{PGF}_{2 \alpha}$ in intramuscular $(0 \mathrm{~h})(25 \mathrm{mg}$ Dinoprost $=\mathrm{PGF}_{2 \alpha}, 5.0 \mathrm{ml}$ Dinolytic, Pfizer, Berlin, Germany), and ovaries were collected by ovariectomy (Shirasuna et al. 2010) through the vagina at 0 (before $\mathrm{PGF}_{2 \alpha}$ injection), $30 \mathrm{~min}$, $2 \mathrm{~h}$ (as the phase of functional luteolysis), and $12 \mathrm{~h}$ (as the phase of starting structural luteolysis).

To use immunohistochemical analysis, CLs were fixed with $4 \%$ paraformaldehyde and embedded in OCT compound according to make frozen tissue specimens. The $\mathrm{CL}$ tissue samples were collected, minced, and then immediately placed into a $1.5 \mathrm{ml}$ microcentrifuge tube with or without $400 \mu \mathrm{l}$ TRIzol reagent and stored at $-80{ }^{\circ} \mathrm{C}$ until analysis. Immunohistochemical and molecular analyses were performed in Obihiro University, Japan.

\section{Culture of LECs, LyECs, and luteal cells}

\section{LEC culture}

LECs were used in this study following the method described by Spanel-Borowski (1991). Cytokeratin-negative LECs isolated from the CLs of the cows during the mid-luteal phase were used as described previously (Spanel-Borowski 1991, Tscheudschilsuren et al. 2002). Briefly, small pieces of the CL tissue were disintegrated and the fragments were serially sieved through nylon meshes with pore sizes of $70 \mu \mathrm{m}$. Cells were seeded on 24-well culture plate, and colony of endothelial cells was monitored and selected by microscopy observation (Spanel-Borowski 1991, Tscheudschilsuren et al. 2002). These cells maintained a stable phenotype during long-term culture. LECs were grown on plates precoated with $1 \%$ Vitrogen in DMEM/F-12 medium containing 5\% FBS, 2.2\% $\mathrm{NaHCO}_{3}, 0.1 \%$ gentamicin solution, and $1 \%$ amphotericin B solution.
All experiments in the present study were carried out on LECs from passages 5 to 8 . To determine the purity of isolated LECs, these LECs expressed typical endothelial cell marker, VWF, by immunohistochemical analysis (data not shown).

\section{LyEC culture}

LyECs were isolated in our laboratory using the method described by Nitta et al. (2011). Briefly, fresh sections of the internal iliac lymphatic vessels were taken from cattle, and the lymph vessels were infused with a solution of $1.5 \mathrm{mg} / \mathrm{ml}$ collagenase in PBS. The vessels were occluded at both ends to trap the enzyme solution and incubated in PBS at $37^{\circ} \mathrm{C}$ for $15 \mathrm{~min}$. The released endothelial lining cells were collected, washed seven times with PBS, and LyECs were grown on plates precoated with $1 \%$ Vitrogen in DMEM/F-12 medium containing $5 \% \mathrm{FBS}, 2.2 \% \mathrm{NaHCO}_{3}, 0.1 \%$ gentamicin solution, and $1 \%$ amphotericin B solution. All experiments in the present study were carried out on LyECs from passages 5 to 8 . To determine the purity of isolated LyECs, these LyECs expressed typical LyEC marker, LYVE1, by immunohistochemical analysis (data not shown) (Nitta et al. 2011).

\section{Steroidogenic luteal cell (SC) culture}

The CLs of the mid-luteal phase were collected at local slaughterhouse, and dispersed using collagenase IV. The luteal stages were classified as mid (days 10-12) by macroscopic observation of the ovary as described previously (Miyamoto et al. 1992). SCs were used in this study following the method described by Klipper et al. (2004). Briefly, SCs were isolated from the bovine mid-CL (days 8-12 of the estrous cycle) using magnetic tosylactivated beads coating with BS-1 lectin (binds glycoproteins on the bovine endothelial cells), indicating that BS-1-positive cells are endothelial cells. In the present study, BS-1-negative cells were assessed as SCs as described previously (Klipper et al. 2004). SCs were grown in DMEM/F-12 medium containing 5\% FBS, 2.2\% $\mathrm{NaHCO}_{3}$, $0.1 \%$ gentamicin solution, and $1 \%$ amphotericin B solution. To determine the purity of isolated SCs, these SCs predominantly expressed typical steroidogenic luteal cell marker, steroid acute regulatory protein by real-time RT-PCR analysis (data not shown). All cells including LECs, LyECs, and SCs were isolated in Obihiro University, Japan.

Before treatment of VEGFA and VASH1, LECs and LyECs were washed twice with PBS. Cells were incubated in DMEM/F-12 medium containing $0.1 \% \mathrm{FBS}, 2.2 \% \mathrm{NaHCO}_{3}, 0.1 \%$ gentamicin solution, and $1 \%$ amphotericin B solution for $24 \mathrm{~h}$ at $37^{\circ} \mathrm{C}$ with the following additions: control (no further addition), $\operatorname{VEGFA}(1,10$, or $100 \mathrm{ng} / \mathrm{ml})$, or VASH1 $(1,10$, or $100 \mathrm{ng} / \mathrm{ml})$. Each treatment was performed in duplicate in 24 -well plates. At the end of the treatment period, the cells were stored at $-80^{\circ} \mathrm{C}$ until analysis of mRNA and protein expression. At least four experiments were performed, with each concentration of agents tested with two replicates/experiments.

\section{Immunohistochemistry}

Serial sections, $7 \mu \mathrm{m}$ thick, of the CLs were mounted on glass microscope slides coated with APS and immunohistochemistry 
for VASH1, LYVE1 (a specific marker of LyECs), and VWF (a specific marker of endothelial cells) was performed. Sections were deparaffinized in xylene and rehydrated using decreasing concentrations of ethanol. The sections were incubated in Tris buffer (pH 10) at $98{ }^{\circ} \mathrm{C}$ for 10 min and immersed in $0.3 \% \mathrm{H}_{2} \mathrm{O}_{2}$ in methanol for $1 \mathrm{~h}$ to block endogenous peroxidase activity. Sections were then rinsed with TBS, incubated with 4\% Block Ace in TBS to reduce nonspecific reactions, and incubated with polyclonal antibody against VASH1 (diluted 1:100), LYVE1 (diluted 1:200), or VWF (diluted $1: 200$ ) at $4{ }^{\circ} \mathrm{C}$ overnight. As a negative control, the sections were incubated with goat antirabbit IgG overnight at $4{ }^{\circ} \mathrm{C}$. Thereafter, sections were rinsed three times for $5 \mathrm{~min}$ in TBS and incubated with biotinylated goat anti-rabbit $\operatorname{lgG}(1: 400)$ at room temperature for $1 \mathrm{~h}$. Sections were then incubated with avidin-biotin reagent $(1: 2)$ for $30 \mathrm{~min}$, and positive signals were visualized using $0.02 \%$ $3,3^{\prime}$-diaminobenzidine tetrahydrochloride (DAB) in $50 \mathrm{mM}$ Tris- $\mathrm{HCl}\left(\mathrm{pH}\right.$ 7.4) containing $0.02 \% \mathrm{H}_{2} \mathrm{O}_{2}$ followed by nuclear staining with hematoxylin.

\section{Proliferation of LECS and LyECS}

LECs and LyECs $\left(5 \times 10^{3}\right.$ cells/well in 96-well plates) were seeded on plates precoated with $1 \%$ Vitrogen in DMEM/F-12 medium containing $0.1 \% \mathrm{FBS}, 2.2 \% \mathrm{NaHCO}_{3}, 0.1 \%$ gentamicin solution, and $1 \%$ amphotericin $\mathrm{B}$ solution, then the cells were exposed to VEGFA (1, 10, or $100 \mathrm{ng} / \mathrm{ml})$, VASH1 $(100 \mathrm{ng} / \mathrm{ml})$, or their combinations for $24 \mathrm{~h}$ at $37^{\circ} \mathrm{C}$. After $24 \mathrm{~h}$, the cell proliferation was determined by the Cell Proliferation Reagent WST-1 kit (Roche). After adding WST-1 reagent, the cells were incubated for $4 \mathrm{~h}$ at $37^{\circ} \mathrm{C}$. The absorbance was read at $450 \mathrm{~nm}$ using microplate reader. At least four experiments were performed, with each concentration of agents tested with three replicates/experiments.

\section{Capillary tube formation on matrigel of LECs and LyECs}

LEC and LyEC capillary tube formation was evaluated as previously described (Jiemtaweeboon et al. 2011, Nitta et al. 2011). Briefly, 48-well plates were coated with $200 \mu \mathrm{l} /$ well of BD matrigel basement membrane at $4{ }^{\circ} \mathrm{C}$ and then incubated at $37^{\circ} \mathrm{C}$ for at least $1 \mathrm{~h}$ to allow polymerization. The cells $\left(2 \times 10^{4}\right.$ cells/well) were plated in a final volume of $0.5 \mathrm{ml} /$ well of culture medium containing VEGFA (10 or $100 \mathrm{ng} / \mathrm{ml}$ ), VASH1 $(100 \mathrm{ng} / \mathrm{ml})$, or their combinations. After incubation for $8 \mathrm{~h}$, tube formation was examined visually and three randomly chosen images taken by inverted microscopy at a magnification of $\times 100$ were imported and the total length of tube formation in each image $(1 \times 1 \mathrm{~mm})$ was analyzed. Data are shown as mean \pm S.E.M. At least four experiments were performed, with each concentration of agents tested with two replicates/experiments.

\section{RNA extraction, cDNA synthesis, and reverse-transcription quantitative $P C R$}

Total RNA was extracted from CL, PBMC, PMN, LyECs, LECs, and LCs following the protocol of Chomczynski \& Sacchi (1987) using TRIzol reagent, treated with DNase using a commercial kit, and frozen at $-20{ }^{\circ} \mathrm{C}$ in THE RNA Storage Solution. The cDNA was synthesized as previously described (Watanabe et al. 2006). The mRNA expression levels of VEGFA, VASH1, and $\beta$-actin were quantified by RT quantitative PCR (RT-qPCR) as previously described (Watanabe et al. 2006). The primers used for real-time PCR were as follows: 5'-atttcaagccgtcctgtgt- 3 ', forward and 5'-tatgtgctggctttggtgag-3', reverse for VEGFA (accession no. MN_174216); 5'-cagtcaaggatttggggatg-3', forward and $5^{\prime}$-accccggttaacaaagaagg- ${ }^{\prime}$, reverse for VASH1 (accession no. MN_001206803.1), and 5'-ccaaggccaaccgtgagaaaat-3', forward and $5^{\prime}$-ccacattccgtgaggatcttca-3', reverse for $\beta$-actin (accession no. MN_173979.3). RT-qPCRs were performed in duplicate in a final volume of $10 \mu \mathrm{l}$ containing $5 \mu \mathrm{l}$ of SYBER Green, $2.8 \mu \mathrm{l}$ of $\mathrm{H}_{2} \mathrm{O}, 0.1 \mu \mathrm{l}$ of $50 \mu \mathrm{M}$ forward and reverse primers, and $2 \mu \mathrm{l}$ of cDNA template or water (as nontemplate negative control). RT-qPCR conditions were as follows: $10 \mathrm{~min}$ at $95{ }^{\circ} \mathrm{C}$, followed by 40 cycles of $95^{\circ} \mathrm{C}$ for $15 \mathrm{~s}, 58^{\circ} \mathrm{C}$ for $20 \mathrm{~s}$, and $72{ }^{\circ} \mathrm{C}$ for $20 \mathrm{~s}$ using a LightCycler (Roche Diagnostics Co.). The PCR products were subjected to electrophoresis, and the target bands were cut out and purified using a DNA purification kit (SUPRECTM-01). The mRNA expression levels were normalized using $\beta$-actin as an internal standard.

\section{Western blotting}

The $\mathrm{CL}$ tissue samples were homogenized in lysis buffer containing $25 \mathrm{mM}$ Tris- $\mathrm{HCl} \mathrm{pH} 7.4,0.3 \mathrm{M}$ sucrose, $2 \mathrm{mM}$ $\mathrm{Na}_{2}$ EDTA, and Protease Inhibitor Cocktail, and then filtered with a $70-\mu \mathrm{m}$ filter. The proteins were dissolved in sample buffer $(0.5 \mathrm{M}$ Tris- $\mathrm{HCl} \mathrm{pH}$ 6.8, glycerol, $10 \%$ SDS, $0.5 \%$ bromophenol blue) and steamed for $5 \mathrm{~min}$. The entire samples were subjected to electrophoresis on $10 \%$ SDS-PAGE gels for $50 \mathrm{~min}$ at $200 \mathrm{~V}$. The proteins were transferred to PVDF membranes for $2 \mathrm{~h}$ at $60 \mathrm{~V}$. The membranes were blocked with 4\% Block Ace Powder in TBS with 0.5\% Tween-20 for $1 \mathrm{~h}$ at room temperature. The membranes were next incubated with a rabbit anti-human-VASH1 polyclonal antibody $(1: 500$ dilution) and a mouse anti- $\beta$-actin monoclonal clone AC-15 antibody (1:10 000 dilution). The membranes were then washed three times in TBS with $0.5 \%$ Tween-20, incubated with HRP-conjugated anti-rabbit (1:10 000 dilution) or antimouse (1:10 000 dilution) IgG antibodies for $1 \mathrm{~h}$ at room temperature, and washed three times with TBS with $0.5 \%$ Tween-20. The signals were detected using an ECL Western Blotting Detection System. The optical densities of the immunospecific bands were quantified using an NIH image computer-assisted analysis system.

\section{Statistical analysis}

All data are presented as mean \pm S.E.M. The statistical significance of differences was assessed by one-way ANOVA followed by Bonferroni's multiple comparison test or Student's $t$-test. A $P<0.05$ was considered significant.

\section{Declaration of interest}

The authors declare that there is no conflict of interest that could be perceived as prejudicing the impartiality of the research reported. 


\section{Funding}

This study was supported by a Grant-in-Aid for Scientific Research of the Japan Society for the Promotion of Science (JSPS) and the Global COE Program, Ministry of Education, Culture, Sports, Science and Technology, Japan.

\section{References}

Acosta TJ, Yoshizawa N, Ohtani M \& Miyamoto A 2002 Local changes in blood flow within the early and midcycle corpus luteum after prostaglandin $\mathrm{F}(2 \alpha)$ injection in the cow. Biology of Reproduction 66 651-658. (doi:10.1095/biolreprod66.3.651)

Augustin HG, Braun K, Telemenakis I, Modlich U \& Kuhn W 1995 Ovarian angiogenesis. Phenotypic characterization of endothelial cells in a physiological model of blood vessel growth and regression. American Journal of Pathology 147 339-351.

Berisha B, Schams D, Kosmann M, Amselgruber W \& Einspanier R 2000 Expression and tissue concentration of vascular endothelial growth factor, its receptors, and localization in the bovine corpus luteum during estrous cycle and pregnancy. Biology of Reproduction 63 1106-1114. (doi:10.1095/biolreprod63.4.1106)

Berisha B, Meyer HH \& Schams D 2010 Effect of prostaglandin $F_{2 \alpha}$ on local luteotropic and angiogenic factors during induced functional luteolysis in the bovine corpus luteum. Biology of Reproduction 82 940-947. (doi:10.1095/biolreprod.109.076752)

Cavicchio VA, Pru JK, Davis BS, Davis JS, Rueda BR \& Townson DH 2002 Secretion of monocyte chemoattractant protein-1 by endothelial cells of the bovine corpus luteum: regulation by cytokines but not prostaglandin $\mathrm{F}_{2 \alpha}$. Endocrinology 143 3582-3589. (doi:10.1210/en.2002-220388)

Chomczynski P \& Sacchi N 1987 Single-step method of RNA isolation by acid guanidinium thiocyanate-phenol-chloroform extraction. Analytical Biochemistry 162 156-159. (doi:10.1016/0003-2697(87)90021-2)

Good DJ, Polverini PJ, Rastinejad F, Le Beau MM, Lemons RS, Frazier WA \& Bouck NP 1990 A tumor suppressor-dependent inhibitor of angiogenesis is immunologically and functionally indistinguishable from a fragment of thrombospondin. PNAS 87 6624-6628. (doi:10.1073/pnas.87.17.6624)

Heishi T, Hosaka T, Suzuki Y, Miyashita H, Oike Y, Takahashi T, Nakamura T, Arioka S, Mitsuda Y, Takakura T et al. 2010 Endogenous angiogenesis inhibitor vasohibin1 exhibits broad-spectrum antilymphangiogenic activity and suppresses lymph node metastasis. American Journal of Pathology 176 1950-1958. (doi:10.2353/ajpath.2010. 090829)

Hojo T, Al-Zi'abi MO, Skarzynski DJ, Acosta TJ \& Okuda K 2009 Changes in the vasculature of bovine corpus luteum during the estrous cycle and prostaglandin $\mathrm{F}_{2 \alpha}$-induced luteolysis. Journal of Reproduction and Development 55 512-517. (doi:10.1262/jrd.20257)

Hosaka T, Kimura H, Heishi T, Suzuki Y, Miyashita H, Ohta H, Sonoda H, Moriya T, Suzuki S, Kondo T et al. 2009 Vasohibin-1 expression in endothelium of tumor blood vessels regulates angiogenesis. American Journal of Pathology 175 430-439. (doi:10.2353/ajpath.2009.080788)

Jiemtaweeboon S, Shirasuna K, Nitta A, Kobayashi A, Schuberth HJ, Shimizu T \& Miyamoto A 2011 Evidence that polymorphonuclear neutrophils infiltrate into the developing corpus luteum and promote angiogenesis with interleukin-8 in the cow. Reproductive Biology and Endocrinology 9 79. (doi:10.1186/1477-7827-9-79)

Kern J, Bauer M, Rychli K, Wojta J, Ritsch A, Gastl G, Gunsilius E \& Untergasser G 2008 Alternative splicing of vasohibin-1 generates an inhibitor of endothelial cell proliferation, migration, and capillary tube formation. Arteriosclerosis, Thrombosis, and Vascular Biology 28 478-484. (doi:10.1161/ATVBAHA.107.160432)

Kimura H, Miyashita H, Suzuki Y, Kobayashi M, Watanabe K, Sonoda H, Ohta H, Fujiwara T, Shimosegawa T \& Sato Y 2009 Distinctive localization and opposed roles of vasohibin-1 and vasohibin-2 in the regulation of angiogenesis. Blood 113 4810-4818. (doi:10.1182/blood2008-07-170316)

Klipper E, Gilboa T, Levy N, Kisliouk T, Spanel-Borowski K \& Meidan R 2004 Characterization of endothelin-1 and nitric oxide generating systems in corpus luteum-derived endothelial cells. Reproduction $\mathbf{1 2 8}$ 463-473. (doi:10.1530/rep.1.00271)
Li D, Zhou K, Wang S, Shi Z \& Yang Z 2010 Recombinant adenovirus encoding vasohibin prevents tumor angiogenesis and inhibits tumor growth. Cancer Science 101 448-452. (doi:10.1111/j.1349-7006.2009. 01388.x)

McCracken JA, Schramm W, Barcikowski B \& Wilson L Jr 1981 The identification of prostaglandin $F_{2 \alpha}$ as a uterine luteolytic hormone and the hormonal control of its synthesis. Acta Veterinaria Scandinavica. Supplementum 77 71-88.

Miyake K, Nishida K, Kadota Y, Yamasaki H, Nasu T, Saitou D, Tanabe K, Sonoda H, Sato Y, Maeshima Y et al. 2009 Inflammatory cytokineinduced expression of vasohibin-1 by rheumatoid synovial fibroblasts. Acta Medica Okayama 63 349-358.

Miyamoto A \& Schams D 1991 Oxytocin stimulates progesterone release from microdialyzed bovine corpus luteum in vitro. Biology of Reproduction 44 1163-1170. (doi:10.1095/biolreprod44.6.1163)

Miyamoto A, Okuda K, Schweigert FJ \& Schams D 1992 Effects of basic fibroblast growth factor, transforming growth factor- $\beta$ and nerve growth factor on the secretory function of the bovine corpus luteum in vitro. Journal of Endocrinology 135 103-114. (doi:10.1677/joe.0.1350103)

Miyamoto Y, Skarzynski DJ \& Okuda K 2000 Is tumor necrosis factor $\alpha$ a trigger for the initiation of endometrial prostaglandin $F(2 \alpha)$ release at luteolysis in cattle? Biology of Reproduction 62 1109-1115. (doi:10.1095/biolreprod62.5.1109)

Nasu T, Maeshima Y, Kinomura M, Hirokoshi-Kawahara K, Tanabe K, Sugiyama H, Sonoda H, Sato Y \& Makino H 2009 Vasohibin-1, a negative feedback regulator of angiogenesis, ameliorates renal alterations in a mouse model of diabetic nephropathy. Diabetes $\mathbf{5 8}$ 2365-2375. (doi:10.2337/db08-1790)

Neuvians TP, Berisha B \& Schams D 2004 Vascular endothelial growth factor (VEGF) and fibroblast growth factor (FGF) expression during induced luteolysis in the bovine corpus luteum. Molecular Reproduction and Development 67 389-395. (doi:10.1002/mrd.20032)

Nimmagadda S, Geetha-Loganathan P, Prols F, Scaal M, Christ B \& Huang R 2007 Expression pattern of vasohibin during chick development. Developmental Dynamics 236 1358-1362. (doi:10.1002/dvdy. 21134)

Niswender GD, Reimers TJ, Diekman MA \& Nett TM 1976 Blood flow: a mediator of ovarian function. Biology of Reproduction 14 64-81. (doi:10.1095/biolreprod14.1.64)

Nitta A, Shirasuna K, Haneda S, Matsui M, Shimizu T, Matsuyama S, Kimura K, Bollwein H \& Miyamoto A 2011 Possible involvement of IFNT in lymphangiogenesis in the corpus luteum during the maternal recognition period in the cow. Reproduction 142 879-892. (doi:10.1530/REP-11-0157)

O'Reilly MS, Holmgren L, Shing Y, Chen C, Rosenthal RA, Moses M, Lane WS, Cao Y, Sage EH \& Folkman J 1994 Angiostatin: a novel angiogenesis inhibitor that mediates the suppression of metastases by a Lewis lung carcinoma. Cell 79 315-328. (doi:10.1016/0092-8674(94) 90200-3)

O'Reilly MS, Boehm T, Shing Y, Fukai N, Vasios G, Lane WS, Flynn E, Birkhead JR, Olsen BR \& Folkman J 1997 Endostatin: an endogenous inhibitor of angiogenesis and tumor growth. Cell 88 277-285. (doi:10.1016/S0092-8674(00)81848-6)

Penny LA 2000 Monocyte chemoattractant protein 1 in luteolysis. Reviews of Reproduction 5 63-66. (doi:10.1530/ror.0.0050063)

Rodgers RJ, Mitchell MD \& Simpson ER 1988 Secretion of progesterone and prostaglandins by cells of bovine corpora lutea from three stages of the luteal phase. Journal of Endocrinology 118 121-126. (doi:10.1677/joe.0. 1180121)

Sato $Y 2011$ Is vasohibin-1 for more than angiogenesis inhibition? Journal of Biochemistry 149 229-230. (doi:10.1093/jb/mvq152)

Sato Y \& Sonoda H 2007 The vasohibin family: a negative regulatory system of angiogenesis genetically programmed in endothelial cells. Arteriosclerosis, Thrombosis, and Vascular Biology 27 37-41. (doi:10. 1161/01.ATV.0000252062.48280.61)

Schams D \& Berisha B 2004 Regulation of corpus luteum function in cattle - an overview. Reproduction in Domestic Animals 39 241-251. (doi:10.1111/j.1439-0531.2004.00509.x)

Schams D, Amselgruber W, Einspanier R, Sinowatz F \& Gospodarowicz D 1994 Localization and tissue concentration of basic fibroblast growth factor in the bovine corpus luteum. Endocrine 2 907-912. 
Shibuya T, Watanabe K, Yamashita H, Shimizu K, Miyashita H, Abe M, Moriya T, Ohta H, Sonoda H, Shimosegawa T et al. 2006 Isolation and characterization of vasohibin-2 as a homologue of VEGF-inducible endothelium-derived angiogenesis inhibitor vasohibin. Arteriosclerosis, Thrombosis, and Vascular Biology 26 1051-1057. (doi:10.1161/01.ATV. 0000216747.66660.26)

Shimizu K, Watanabe K, Yamashita H, Abe M, Yoshimatsu H, Ohta H, Sonoda H \& Sato $\mathbf{Y} 2005$ Gene regulation of a novel angiogenesis inhibitor, vasohibin, in endothelial cells. Biochemical and Biophysical Research Communications 327 700-706. (doi:10.1016/j.bbrc.2004.12. 073)

Shirasuna K, Sasahara K, Matsui M, Shimizu T \& Miyamoto A 2010 Prostaglandin $F_{2 \alpha}$ differentially affects mRNA expression relating to angiogenesis, vasoactivation and prostaglandins in the early and mid corpus luteum in the cow. Journal of Reproduction and Development $\mathbf{5 6}$ 428-436. (doi:10.1262/jrd.10-004O)

Spanel-Borowski K 1991 Diversity of ultrastructure in different phenotypes of cultured microvessel endothelial cells isolated from bovine corpus luteum. Cell Tissue Research 266 37-49. (doi:10.1007/BF00678709)

Tamaki K, Moriya T, Sato Y, Ishida T, Maruo Y, Yoshinaga K, Ohuchi N \& Sasano H 2009 Vasohibin-1 in human breast carcinoma: a potential negative feedback regulator of angiogenesis. Cancer Science 100 88-94. (doi:10.1111/j.1349-7006.2008.01015.x)

Tombran-Tink J, Chader GG \& Johnson LV 1991 PEDF: a pigment epithelium-derived factor with potent neuronal differentiative activity. Experimental Eye Research 53 411-414. (doi:10.1016/0014-4835(91) 90248-D)

Townson DH, O'Connor CL \& Pru JK 2002 Expression of monocyte chemoattractant protein-1 and distribution of immune cell populations in the bovine corpus luteum throughout the estrous cycle. Biology of Reproduction 66 361-366. (doi:10.1095/biolreprod66.2.361)
Tscheudschilsuren G, Aust G, Nieber K, Schilling N \& Spanel-Borowski K 2002 Microvascular endothelial cells differ in basal and hypoxiaregulated expression of angiogenic factors and their receptors. Microvascular Research 63 243-251. (doi:10.1006/mvre.2001.2346)

Watanabe K, Hasegawa $Y$, Yamashita $H$, Shimizu K, Ding $Y$, Abe $M$, Ohta H, Imagawa K, Hojo K, Maki H et al. 2004 Vasohibin as an endothelium-derived negative feedback regulator of angiogenesis. Journal of Clinical Investigation 114 898-907. (doi:10.1172/JCI21152)

Watanabe S, Shirasuna K, Matsui M, Yamamoto D, Berisha B, Schams D \& Miyamoto A 2006 Effect of intraluteal injection of endothelin type A receptor antagonist on $\mathrm{PGF}_{2 \alpha}$-induced luteolysis in the cow. Journal of Reproduction and Development 52 551-559. (doi:10.1262/jrd.18018)

Yamashita H, Abe M, Watanabe K, Shimizu K, Moriya T, Sato A, Satomi S, Ohta H, Sonoda H \& Sato Y 2006 Vasohibin prevents arterial neointimal formation through angiogenesis inhibition. Biochemical and Biophysical Research Communications 345 919-925. (doi:10.1016/j.bbrc.2006.04.176)

Yoshinaga K, Ito K, Moriya T, Nagase S, Takano T, Niikura H, Yaegashi N \& Sato Y 2008 Expression of vasohibin as a novel endothelium-derived angiogenesis inhibitor in endometrial cancer. Cancer Science $\mathbf{9 9}$ 914-919. (doi:10.1111/j.1349-7006.2008.00777.X)

Zhou SY, Xie ZL, Xiao O, Yang XR, Heng BC \& Sato Y 2010 Inhibition of mouse alkali burn induced-corneal neovascularization by recombinant adenovirus encoding human vasohibin-1. Molecular Vision 16 1389-1398.

Received 4 December 2011

First decision 17 January 2012

Revised manuscript received 19 January 2012

Accepted 24 February 2012 